\title{
AGED ASPHALTIC DIKE REVETMENTS ON (SATURATED) SAND TESTED IN A LARGE DELTAFLUME
}

\author{
Bernadette Wichman and Mark Klein Breteler, Deltares, Bernadette.Wichman@deltares.nl, \\ Arjan de Looff, KIWA KOAC, Arjan.de.Looff@kiwa-koac.com \\ Jan Hateboer, Wetterskip Fryslân, JHateboer@Wetterskipfryslan.nl
}

\section{INTRODUCTION}

In the Netherlands, $600 \mathrm{~km}$ of the sea dikes are protected by an asphaltic revetment which must resist considerable wave loads with a significant wave height of up to $4.5 \mathrm{~m}$. The subsoil is normally sandy, and the asphalt layer can fail as a result of fatigue due to repeated loading under storm conditions (Wichman \& Davise 2016). Fifty years old asphalt has been taken from the Dutch Lauwersmeer dike and placed on a sand body in the large Deltaflume at Deltares, where it is possible to generate large waves (up to 4 meters). It is still unsure how the asphalt will fail, while interacting with the sandy subsoil, depending on the position of the phreatic line, among other factors.

\section{RESEARCH GOAL}

The aim of the research is to determine the resistance of the asphaltic revetment to major wave attack until failure, i.e. when it loses its function to protect the dike from erosion. The position of the phreatic line in the sand has been varied. Insights from these instrumented tests, will lead to improvement and extension of the current safety assessment.

\section{EXPERIMENTAL SET-UP}

In the Deltares Delta Flume two test series were performed, on four asphalt plates $(8 \mathrm{~m} \times 0.5 \mathrm{~m} \times 0.15$ to $0.25 \mathrm{~m}$ ) each, see Figure 1. The first series was on asphalt from the Lauwersmeer dike with a better than average quality, the second series on asphalt with less than average quality. The sand in the first series was less dense (relative density around 0.3 ) than in the second series (relative density around 0.5 ).

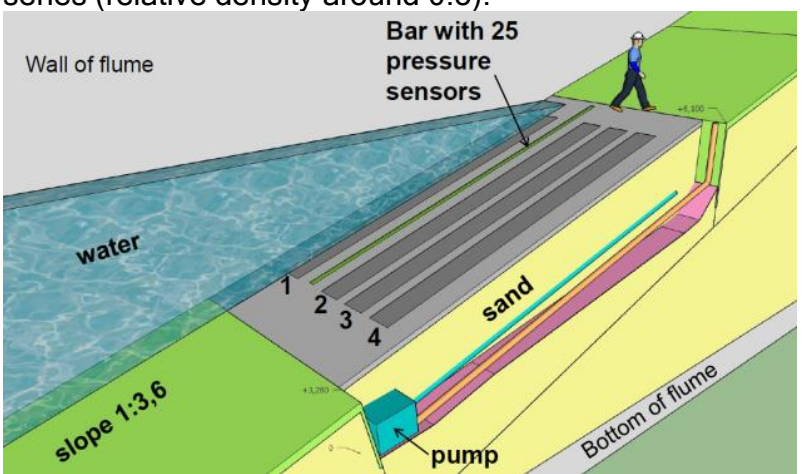

Figure 1 - Asphalt plates 1 to 4 in the Deltares Deltaflume.

The tests with a low phreatic line consisted of 3 series of waves of about 2 hour duration each with significant wave height $\mathrm{H}_{\mathrm{m} 0}=1.6,1.8$ and $2.0 \mathrm{~m}$ on model scale (with $\mathrm{T}_{\mathrm{p}}=5.2,5.5$ and $5.8 \mathrm{~s}$, respectively), followed by a few large single waves ( $3.5 \mathrm{~m}$ high). The first test series with a high phreatic line was carried out with $\mathrm{H}_{\mathrm{m} 0}=1.6 \mathrm{~m}$. The second series uses $\mathrm{H}_{\mathrm{m} 0}=2.0 \mathrm{~m}$. In each test series two asphalt plates were placed as taken from the dike, i.e. with an irregular bottom surface, a third plate was cut to remove this part, and a fourth plate was milled to remove the top $5 \mathrm{~cm}$, that was of less quality asphalt. The strain was measured almost continuously along the sides of the asphalt plates by using glass fibers. Also strain gauges were placed for comparison. Thin wires were placed halfway the asphalt thickness to detect crack growth. In the sand total stress and pore water pressure transducers were placed. Also temperature was measured, being close to $12^{\circ} \mathrm{C}$.

\section{EXPERIMENTAL RESULTS}

The first test series for the better than average asphalt quality on the sand with a relative density of 0.3 gives the following insights: The asphalt deformation after the tests with a low phreatic line was a few centimeters, and the built up of this was gradual, step by step, due to wave action lasting for about 6 hours. The asphalt did not fail in these tests.

During the tests with a high phreatic line (equal to the outside water table) this deformation was much larger, i.e. up to $10 \mathrm{~cm}$ after 1 hour at $\mathrm{H}_{\mathrm{m} 0}=1.6 \mathrm{~m}$, see Figure 2 . After an additional 10 minutes of wave action the asphalt failed, i.e. the sand came out of the joints. This was the case for all four bars.

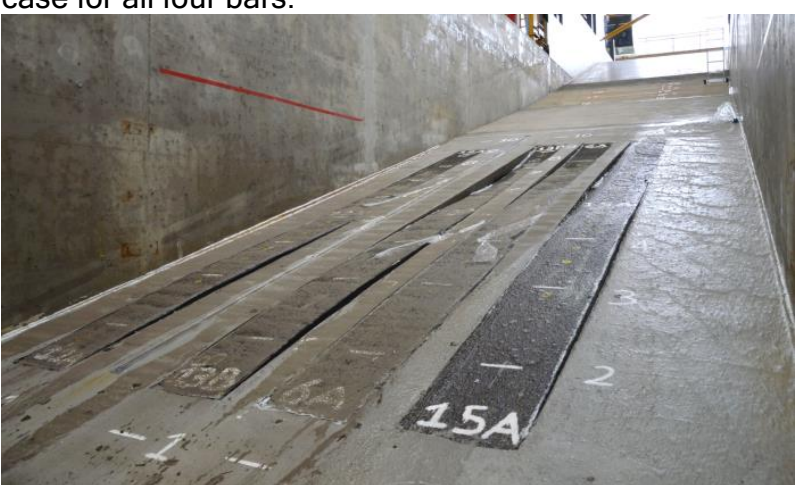

Figure 2 - Asphalt plates 1 to 4 in the Deltares Delta Flume after 60 minutes of wave action with high phreatic line (series 1).

The asphalt plates behaved rather flexible, i.e. only small cracks were observed. The upper part of the asphalt bars was indented and the bottom part was lifted, this occurring gradually in time. This indicates that the sand moved downward.

The second test series, with asphalt of less than average quality on the sand with 0.5 relative density, showed the following behavior: The deformation after the tests at low phreatic line was little (less than a few $\mathrm{mm}$ after about 6 hours of wave action). When the phreatic line was increased up to $1.5 \mathrm{~m}$ below the outward water level (the latter at $6.0 \mathrm{~m}$ above the bottom of the canal) with $\mathrm{H}_{\mathrm{m} 0}=$ $2.0 \mathrm{~m}$, there was still a little deformation (after 2 hours). The test with the phreatic line at $0.7 \mathrm{~m}$ below the outside water level and $\mathrm{H}_{\mathrm{m} 0}=2.0 \mathrm{~m}$, resulted in a small deformation, where the bottom part of the asphalt plates was lifted with about $1 \mathrm{~cm}$ and the top part was indented (after another 2 hours). An existing crack did grow over the whole width of asphalt plate 10A. The asphalt plates with a smaller thickness showed the largest deformation. Next, a test was done with the phreatic line equal to the 
outside water level and $\mathrm{H}_{\mathrm{m} 0}=2.0 \mathrm{~m}$. After 11 minutes of wave action the deformation in the bottom half of the asphalt plates $1 \mathrm{~B}$ en $10 \mathrm{~A}$ increased that much that this was considered to be failure, see Figure 3. A large amount of sand came out and after another 4 minutes of wave action, part of the asphalt was lifted out of the surface, see Figure 3.

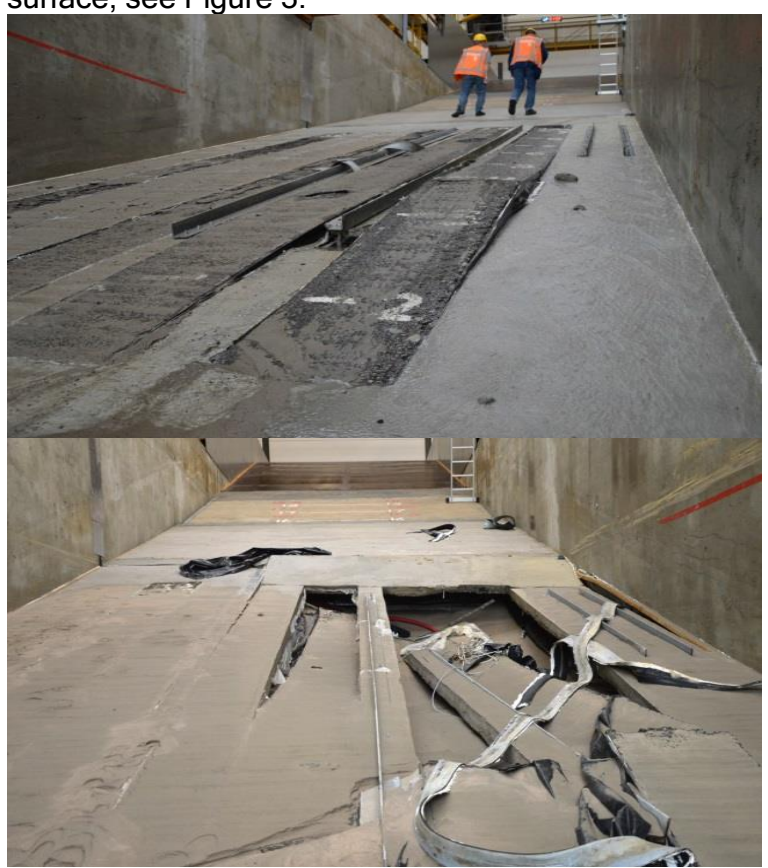

Figure 3 - Asphalt plates 1 to 4 in the Deltares Delta Flume (series 2) after 11 minutes of wave action with high phreatic line (above) and after another 4 minutes of wave action (below).

\section{ANALYSIS}

All wave attacks were analysed by means of the Deltares program ANALYSE WAVE. From this analysis statistical distributions of maximum impact pressure, width of the pressure distribution, and the impact point on the slope were derived. These show that the major part of the impact pressures were relatively low as compared to literature, i.e. in the lower range obtained from experiments with regular waves up to $2 \mathrm{~m}$ wave height, see Führböter, A. \& U. Sparboom 1988.

For a selection of wave attacks from the tests with a low phreatic line, a comparison was made of the measured total stresses in the sand and values from Abaqus calculations, see Figure 4 for an example. These calculations were relatively simple, i.e. static, with linear elastic asphalt and linear elastic sand. In these calculations the asphalt stiffness was determined at the testing temperature (about $15{ }^{\circ} \mathrm{C}$ ) and at the main frequency of the response to wave attack $(5 \mathrm{~Hz})$. It follows that the measured total stresses were significantly (around 0.5 times) lower than calculated. Also the strains were analysed, and it follows that the measured strains are about a factor 4 smaller than calculated. This means that the impact of the load was less than was schematised in the calculation. The pressure distribution at the outside slope, was obtained from one vertical array of sensors, whereas the asphalt plates were on laterally different positions. The impact pressure at the asphalt plates might thus be significantly different (30\%). In addition, dynamic effects occur, that influence the deflections, the strains in the asphalt and the total stresses in the sand.

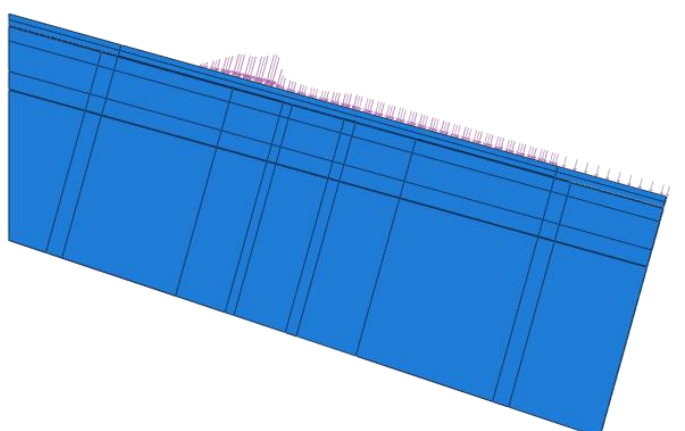

Figure 4 - Pressure distribution in Abaqus on the slope for an example of a single wave attack, maximum pressure $=$ $97.5 \mathrm{kPa}$.

These effects seem to give additional safety, and need further consideration.

The tests with a high phreatic line suggest that there is an uplift of the asphalt plate, just below the zone of wave impact, see Figure 5.

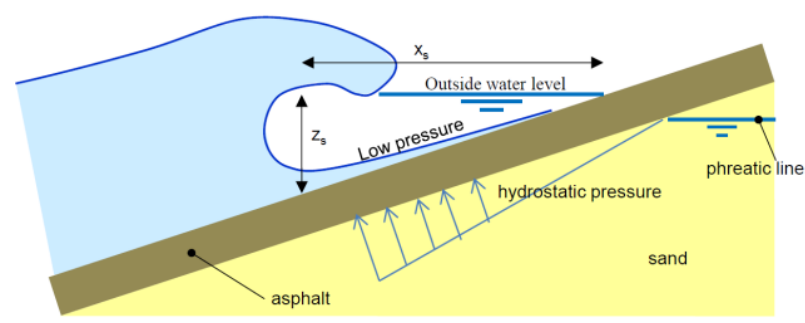

Figure 5 - Hydrostatic pressure difference across the asphalt, causing uplift.

While the asphalt plate is deforming, the sand will move downward, little by little. Finally, this deformation becomes too large and thus failure occurs. In case the phreatic line is low enough, there will be no uplift.

\section{CONCLUSIONS}

Two test series have been performed on old asphalt with rather good and with poor quality, placed on sand with different degree of compaction. The phreatic line in the sand was varied, step by step.

It follows that in case the phreatic line approaches the outside water level, the asphalt fails quickly. In case of a low phreatic line, the asphalt deforms less than expected from simple calculations. Further understanding is needed to apply this to the Dutch dikes.

The current Dutch safely assessment will be adjusted, to take these effects into account.

\section{REFERENCES}

Führböter, A. \& U. Sparboom (1988). Shock pressure interactions on prototype sea dykes caused by breaking waves. Modelling Soil Water_Structure Interactions, 243-252, Balkema, ISBN 9061918154.

Wichman, B.G.H.M. \& M.P. Davidse (2016). Fatigue of asphaltic dike revetments under wave loading: validation and improved modelling. Int. J. of Pavement Eng. Vol. 19 , No.2, 131-144

Acknowledgement: Principal of this research is Wetterskip Fryslân, with financial support from the Dutch HWBP. 